\title{
Study on Operation and Maintenance Method of Distribution Terminal Based on SPM
}

\author{
Xiaojun Chen ${ }^{\mathrm{a}}{ }^{*}$, Wenjie Zheng $^{\mathrm{b}}$, Shu Huang ${ }^{\mathrm{c}}$, Hui Chen ${ }^{\mathrm{d}}$ \\ Electric Power Research Institute of Guangdong Power Grid Corporation \\ Limited,Guangzhou,Guangdong 510080, China \\ a chenarmy11@qq.com, b zhengwenjie@gddky.csg.cn, c huangshu@gddky.csg.cn, \\ dchenhui@gddky.csg.cn \\ Corresponding Author. * chenarmy11@qq.com
}

\begin{abstract}
Keywords: Distribution automation; Set pair matching; Parameters configuration; Operation and maintenance method; Automatic identification

Abstract. With the current distribution network automation construction gradually promotion, distribution automation terminal large-scale applied in various regions of the country power grid. In the maintenance of distribution automation terminal operation, many problems was discovered to be widespread, such as terminal variety, manufacturers of different models, the complexity of maintenance mode and so on. In order to solve these problems, the strategy of intelligent operation and maintenance of distribution network automation terminal based on SPM is proposed, which analyze the characteristics and configuration methods of distribution terminal parameter. It can automatically identify the parameters configuration method of distribution terminal and realize the type of terminal by the pair matching analysis. Finally the configuration of the parameters is achieved by the unified maintenance interface. Research shows that: This operation and maintenance method can effectively improve the efficiency of daily operation and maintenance of distribution automation terminal.
\end{abstract}

\section{Introduction}

Distribution automation is the use of modern communication and computer technology for remote monitoring and controlling equipment of distribution network, which will be run online in network systems $^{[1-5]}$. Objects of distribution automation mainly monitored distributed along the feeder line equipment, which is on a large scale and over a broad area. With the current construction of distribution network automation gradually extended, large-scale distribution automation terminal in various regions of the national grid has been applied ${ }^{[6-10]}$.

In the process of the distribution automation terminal operation and maintenance, there are widespread different kinds of problems, such as the widely variety of terminal, different manufacturers models, complex maintenance and so on. There are three kinds of methods mainly used in distribution automation terminal maintenance, such as private statute configuration, the configuration file download mode, remote parameter configuration on WEB interface. The private statute configuration is safely and interactively, but the complex structure is not conducive to post-parameter expansion. The architecture of configuration file download mode is simple and convenient transport, but is not conducive to remote parameter transfer. The parameter configuration on WEB interface is convenient for $\log$ in, but less secure. Based on the characteristics of the different types of terminal parameters analyzed and common study of different configurations, the paper proposes a method of unified configuration parameters of distribution automation terminal, which can enhance distribution automation terminal daily operation and maintenance efficiency.

\section{A unified configuration schema}

At present, there are at least two disadvantages for terminal automation parameters maintenance software of the industries. On the one hand of the software version compatibility, due to development 
of distribution automation technology rapidly, with distribution terminal and maintenance software version are constantly updated, it is easy to encounter problems that new maintenance software is not compatible with the old terminal equipment. For the production operation and maintenance staff of Power Supply Bureau, there are many terminals installed at different times, they need to keep multiple maintenance software versions, which is not conducive to productivity improvement. On the other hand of configuration interface, different manufacturer meats different users interface. The staffs need to spend more time to learn the way of using maintenance software. Diversity interface is also likely to cause confusion configuration for the staffs, resulting in operational errors, which is a greate impact for the production of distribution network security.

In order to assist the operation and maintenance of the terminal by parameters configuration, this paper presents a method of unified distribution automation terminal configuration parameters. It has the following features.

a) Fixed unified maintenance interface

b) Specification of communication for Parameters

c) Compatible flexibility of different types of terminals

d) The integrity of important parameters

e) Interactive configuration

As it is shown in Figure 1, the architecture of terminal unified parameters configuration consists of three parts, which is communication judgment, terminal type identification and configuration parameters. After identifying communication connection of the terminal, it can automatically discern the way of parameters communication used to configure the terminal. Then it will be a smart match of the database server and the terminal type. The staff of distribution network production team can modify parameters through a unified maintenance interface, to achieve the parameters of distribution network terminals.

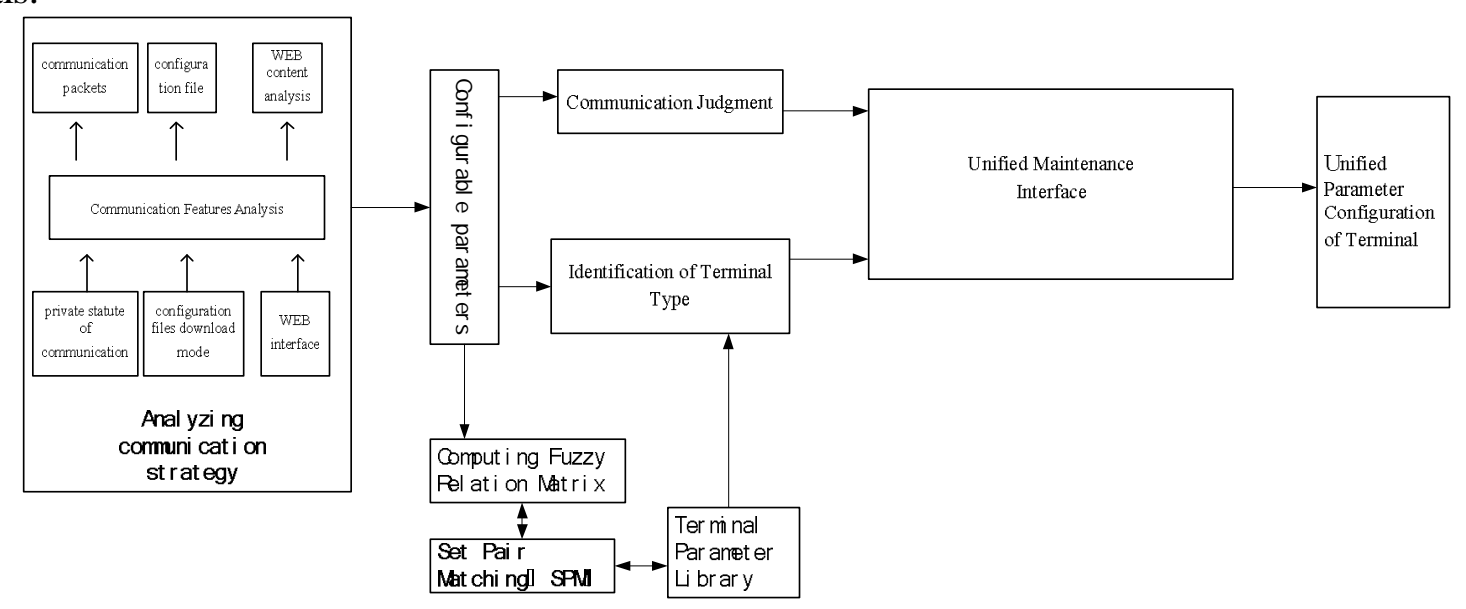

Figure 1 Schematic of unified parameter configuration architecture

\section{Unified parameter configuration of terminal}

\section{Communication judgment}

When the distribution automation terminal maintenance, the communications of host and terminal mainly are three types of remote parameter configuration mode, such as private statute of communication, configuration files download mode and WEB interface. Different configurations have different communication characteristics. More details can be found as Table 1 shows. 
Table 1 Communication Type Characteristics

\begin{tabular}{|l|l|l|l|}
\hline No. & Communication Type & Features & Treatment \\
\hline 1 & $\begin{array}{l}\text { private statute of } \\
\text { communication }\end{array}$ & $\begin{array}{l}\text { communication } \\
\text { packets }\end{array}$ & $\begin{array}{l}\text { Communications packet decoding and } \\
\text { respond }\end{array}$ \\
\hline 2 & $\begin{array}{l}\text { configuration files download } \\
\text { mode }\end{array}$ & configuration file & Configuration file parsing \\
\hline 3 & WEB interface & WEB remote login & WEB page content analysis \\
\hline
\end{tabular}

As it is shown in Figure 2, this paper presents a strategy to automatically determine the parameter communication. Based on characteristics of different ways of communication, a decision logic tree was established by using multiple cycles' round-robin fashion. The criterion for determining parameter communication is whether the configuration parameters are obtained successfully.

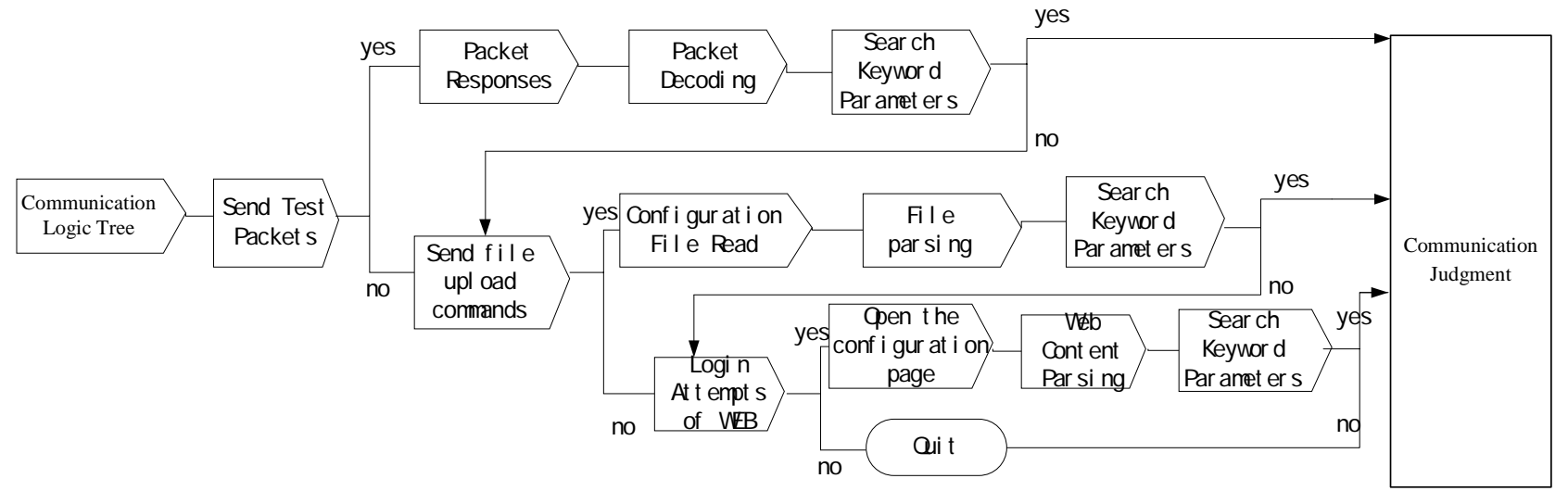

Figure 2 Strategy of Communication Recognition

\section{Identification of terminal type}

With analyzing parameters feature of distribution terminal, the type of terminals can be identified intelligently. Different types of terminals have different features as follows.

a) The main functions of DTU are collecting the parameters of electrical switching station and isolating the line fault. The parameter characteristics are remote telemetry and control parameter configuration.

b) The main functions of FTU are monitoring the states of electrical lines and executing remote control. The parameter characteristics are "three remote" and protection setting value.

c) The main functions of fault indicator are monitoring the states of electrical lines and fault location. The parameter characteristics are "two remote" and less protection setting value.

Due to the characteristics of parameters of different kinds of terminal are partial overlapping, the passing rate of directly parameters matching is not too high。This paper adopted an intelligent matching method based on set pair matching (SPM) theory, to implement intelligent matching of parameters and terminal type.

SPM is a kind of intelligent matching way based on set pair analysis, which is applied in the paper as follows.

a) Confirm the set pair $\mathrm{X}$ and $\mathrm{Y}$ to match. $\mathrm{X}=\left\{x_{1} x_{2} \cdots x_{m}\right], \mathrm{Y}=\left[y_{1} y_{2} \cdots y_{n}\right]$. In the paper, $x_{1} x_{z} \cdots x_{m}$ represent different terminal types, $y_{1} y_{2} \cdots y_{n}$ represent different characteristics of parameters.

b) Solute the matrix of $\mathrm{X} \times \mathrm{Y} . \mathrm{R}=\left(r_{\mathrm{k} 2}\right)_{m \times n} ; k=1,2 \cdots \mathrm{m} ; 1=1,2 \cdots \mathrm{n}$. 


$$
\mathrm{R}=x_{1}\left[\begin{array}{ccc}
y_{1} & \cdots & y_{n} \\
\vdots & \cdots & r_{1 n} \\
x_{m} & \cdots & \vdots \\
r_{m l} & \cdots & r_{m n}
\end{array}\right]
$$

c) Confirm the correlate numbers of every $(k, 1)$ with set pair analysis by $\mu=a+b i+c j \circ$

d) Weighted $\alpha, \beta$, $\gamma$, get the correlate value $\mathrm{v}_{\mathrm{kl}}$ of every (k, 1$)$.

e) Solute the max value.

$$
r_{\max }={ }_{k, l} r_{k 2}
$$

It is the best match.

\section{Unified maintenance interface}

The unified maintenance interface not only can achieve the function of the automated factories, but also can be compatible with various terminal types. And it should be convenient and easy to learn for the staffs. In addition, information security and permissions management cannot be ignored. The User permissions in the paper can be divided into three levels: user level, project level and management level. Three level of user permissions are shown in Figure 3.

The user level has the right to view and modify the network parameters and maintenance port parameters of distribution terminal, such as IP address, com port, bound rate, code type, communication methods and so on.

The project level has the right to view and modify the parameters of "three remote" and fault constant value of different terminals, such as overcurrent, zero sequence current, reclose time of switching and so on.

The management level has the right to view and modify the all parameters of terminals.

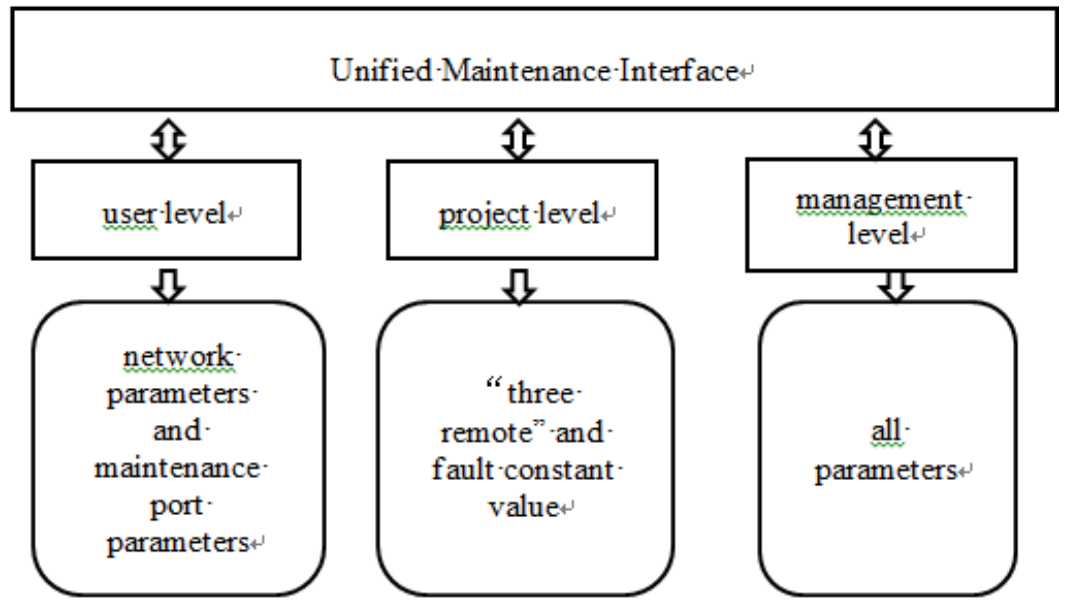

Figure 3 Classification of User Rights

\section{Effect of Contrast}

In order to verify the feasibility and accuracy of the algorithm, this paper selects the parameter configuration software of the mainstream distribution automation manufacturers as the reference objects, comparing by operation time, the use of frequency and fault recovery time. 


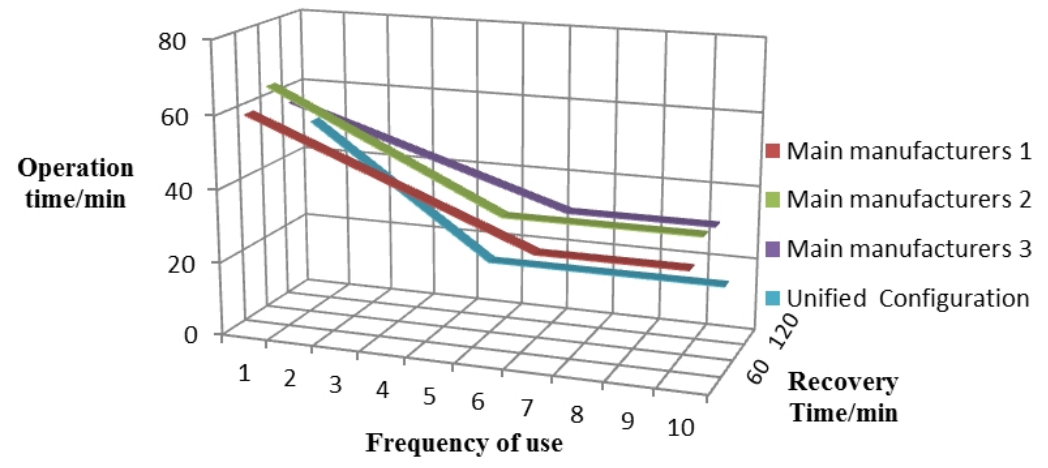

Figure 4 Effect of Contrast

As can be seen from the Figure 4, it can be found that the minimum operating time for the first time of parameter configuration way is unified configuration, which only needs 50 minutes. It illustrates the high acceptance of the distribution network operation and maintenance staffs. After a period of operation experience, the operating time of unified configuration method is stable in 14 minutes, $60 \%$ less than other mainstream manufacturers.

\section{Conclusion}

According to the characteristics of distribution automation configuration parameters configured with a variety of types of communication features, the paper establishes a communication parameter automatic identification logic tree. With set pair matching analysis of the characteristics of terminals, the paper puts forward a smart match by designing a stable and unify interface, which is to achieve a unified distribution terminal configuration function.

The proposed algorithm can solve the problem of distribution terminal operation and maintenance, such as complex objects, tools version diverse, low operation and maintenance efficiency. It can be widely used in the distribution operation and maintenance of automated production. If it is promoted to full use of the Guangdong power grid, it will effectively improve the production efficiency of the distribution maintenance for frontline team staffs.

\section{Acknowledgement}

This work was supported in part by science and technology program of China Southern Power Grid under grant K-GD2013-0482.

\section{References}

[1] ZHANG Xiaoping, YU Nanhua. Analysis on Construction and Development of Communication System for Smart Distribution Grid [J]. Guangdong Electric Power , 2011 , 24(11) : 59-65.

[2] CUI Houkun, CHEN Yun. Discussion on the Distribution Automation System in Nanjing[J]. Telecommunications for Electric Power System. 2011(07) : 16-19.

[3] Lin Gongping. TECHNIQUE STRATEGY OF FEEDER AUTOMATION OF DISTRIBUTION POWER NETWORK[J]. Automation of Electric Power Systems. 2001(07) : 33-38.

[4] XIAO Shijie. Consideration of technology for constructing Chinese smart grid[ $\mathrm{J}]$. Automation of Electric Power Systems , 2009 , 33 ( 16 ) : 1-4. 
[5] ZHANG Wenliang ,LIU Zhuangzhi ,WANG Mingjun ,et al . Research status and development trend of smart grid [ J ] . Power System Technology , 2009 , 33 ( 13 ) : 1-11.

[6] Hany E. Farag, E.F.El-Saadany, L.El Chaar. "A Multilayer Control Framework for Distribution Systems with High DG Penetration", 2011 International Conference on Innovations in information Technology, 2011,4:94-99.

[7] Martins, V.F, Borges, C.L.T. "Active distribution network integrated planning incorporating distributed generation and load response uncertainties", IEEE Transactions on power systems, 2011,99:1-9.

[8] QIN Lijun, LIU Lin , SHI Junfeng, et al. Distribution automation system under IEC61850 system [ J ] . Electrical Equipment , 2007,8 ( 12 ) : 13-15.

[9] MCGRANAGHAN M , GOODMAN F. Technical and system requirements for advanced distribution automation[ C ]\| 18th International Conference on Electricity Distribution. Turin , Italy : [s.n. ] , $2005: 1-5$.

[10] XU Bingyin ,LI Tianyou ,XUE Yongduan. Smart distribution grid and distribution automation [ J ] . Automation of Electric Power Systems , 2009 , 33 ( 17 ) : 38-41. 